\title{
O EFEITO DO OXIGÊNIO NAS PROPRIEDADES DO VERGALHÃO DE COBRE ELETROLÍTICO*
}

\author{
Bruno de Paulo Silva ${ }^{1}$ \\ Vinícius Matos Quintão² \\ Márcio Fernandes Caria ${ }^{3}$
}

\begin{abstract}
Resumo
O cobre é um dos metais mais utilizados desde os primórdios da indústria, principalmente para a fabricação de fios e cabos para fins elétricos. Dentre as diversas propriedades do cobre, as mais importantes são: capacidade que o material tem de conduzir corrente elétrica e quantidade de energia utilizada para realizar 0 recozimento garantindo o alongamento especificado. Essas propriedades são diretamente influenciadas pelo teor de oxigênio adicionado como elemento de liga durante a fabricação do vergalhão de cobre eletrolítico. Neste contexto, o artigo tem o objetivo de apresentar como realizar o controle do oxigênio no processo de laminação e quais as influências desse elemento para diminuir os custos com energia elétrica, reduzir as quebras no processo de trefilação e aumentar a condutividade elétrica dos produtos de cobre.
\end{abstract}

Palavras-chave: Alongamento; Condutividade elétrica; Recozimento; Influência do oxigênio.

\section{THE EFFECT OF OXYGEN ON THE PROPERTIES OF COPPER ROD ETP}

\begin{abstract}
Copper is one of the most used metals in the world, mostly to produce electric cables. Among the properties of copper, the most important are: electrical conductivity and the quantity of energy used to annealing ensuring the proper elongation. The properties of copper are affected by the addition of oxygen as alloying element during the production of electrolytic tough picth coppers (ETP). This paper intends to show the effect of oxygen on properties of rod and wire copper. Besides, show how to control this element during the production of electrolytic copper rod to reduce fractures in drawing, the costs with energy and increase electrical conductivity of copper products.
\end{abstract}

Keywords: Elongation; Electrical conductivity; Annealing; Effects of oxygen.

1 Engenharia Metalúrgica, Engenheiro Especialista, Chefe de Departamento, Produtos Laminados e Laboratório, Paranapanema, Dias D’Ávila, Bahia, Brasil.

2 Engenharia Metalúrgica, Engenheiro, Engenheiro de Processos, Tecnologia e Processos, Paranapanema, Dias D’Ávila, Bahia, Brasil.

3 Administração de empresas, Administrador, Técnico Líder, Produtos Laminados, Paranapanema, Dias D’Ávila, Bahia, Brasil. 


\section{INTRODUÇÃO}

A qualidade dos vergalhões de cobre é avaliada através de análises químicas e indiretamente por diversos ensaios físicos, mecânicos e elétricos. A composição química é determinada pelo cátodo utilizado para produzir o vergalhão, exceto o teor de oxigênio que é considerado um elemento de liga, pois este é intencionalmente adicionado como um gás durante a fundição do cobre, agindo como um elemento desoxidante para as impurezas metálicas, portanto, muitos benefícios podem ser alcançados. O método utilizado para controle e os efeitos do oxigênio nos produtos de cobre serão discutidos neste artigo.

Embora o assunto seja complexo, praticamente todos os autores concordam que o baixo ou elevado teor de oxigênio pode prejudicar as propriedades mecânicas do vergalhão ou do fio de cobre. Portanto, para realizar o controle do oxigênio e diminuir a variabilidade no processo é necessário realizar ações rápidas utilizando um equipamento de medição contínua para manter o oxigênio dentro da faixa adequada buscando sempre atingir os melhores resultados nos ensaios realizados.

Dos ensaios mecânicos realizados no vergalhão, a cinética de recristalização é a principal propriedade avaliada. Esta propriedade do cobre é influenciada pela composição química (teor de impurezas), pelas variáveis termomecânicas (grau de deformação, temperatura e tempo de recozimento) e pelo teor de oxigênio. O oxigênio influencia, favoravelmente, a cinética de recristalização do cobre, pois o oxigênio diminui a temperatura de recristalização, além disso, ele formaria precipitados com as impurezas, o que representa menor impacto na cinética de recristalização, comparado quando as impurezas permanecem em solução sólida [1].

A condutividade elétrica é o ensaio realizado para determinar quanto o cobre conduz de corrente elétrica. Segundo a norma "International Annealed Copper Standard" (IACS), adotada em praticamente todos os países, é fixada em $100 \%$ a condutividade de um fio de cobre de 1 metro de comprimento com $1 \mathrm{~mm} 2$ de seção e cuja resistividade a $20^{\circ} \mathrm{C}$ seja de $0,01724 \mathrm{~W} \cdot \mathrm{mm}^{2} / \mathrm{m}$. Dessa forma, esse é o padrão de condutividade adotado, o que significa que todos os demais condutores, sejam em cobre, alumínio ou outro metal qualquer, têm suas condutividades sempre referidas a aquele condutor [2].

O baixo teor de oxigênio limita a condutividade do vergalhão de cobre, podendo não atender a especificação mínima de $101,0 \%$ IACS a $20^{\circ} \mathrm{C}$ [1]. Por outro lado, o elevado teor de oxigênio pode provocar a formação de grande quantidade de óxido cuproso $\left(\mathrm{Cu}_{2} \mathrm{O}\right)$, podendo diminuir a ductilidade e ocorrer à quebra frágil do fio de cobre durante o processo de trefilação. O diagrama de fases Cu-O (Figura 1) mostra a formação de óxido cuproso durante a solidificação [1]. 


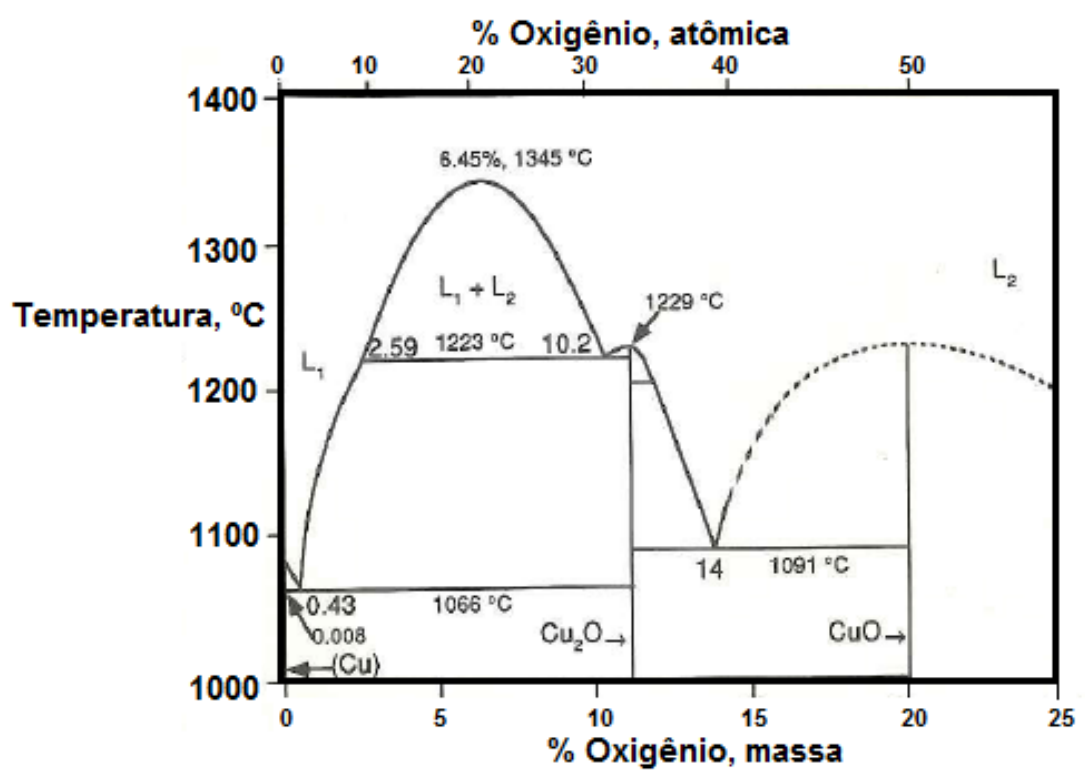

Figura 01. Diagrama de fases do cobre-oxigênio [1].

Nota-se que o cobre apresenta baixa solubilidade para o oxigênio, o que possibilita a precipitação de óxido cuproso $(\mathrm{Cu} 2 \mathrm{O}) \cdot \mathrm{A} 1083^{\circ} \mathrm{C}$ o cobre permite $80 \mathrm{ppm}$ de oxigênio em solução sólida, mas essa solubilidade diminui durante o resfriamento [1].

O oxigênio é benéfico para o vergalhão de cobre na medida em que reage com impurezas não metálicas provocando sua precipitação a partir da matriz, diminuindo a temperatura de recristalização e o tempo necessário para o "amolecimento". Esse benefício é parcialmente prejudicado pelo pequeno efeito da presença de uma dispersão de partículas de óxidos precipitadas. Existe um compromisso entre esses dois efeitos e um teor ótimo de oxigênio $[1,6]$. Esta escolha é ditada de acordo com as propriedades mostradas na Figura 2. Onde para propriedade elétrica, de 0 a 200ppm de oxigênio a condutividade elétrica aumenta devido ao efeito desoxidante, pois o oxigênio reduz a quantidade de elementos residuais remanescentes em solução sólida. E de 200 a 650ppm a condutividade elétrica diminui devido ao elevado teor do óxido cuproso ( $\left.\mathrm{Cu}_{2} \mathrm{O}\right)[1]$.
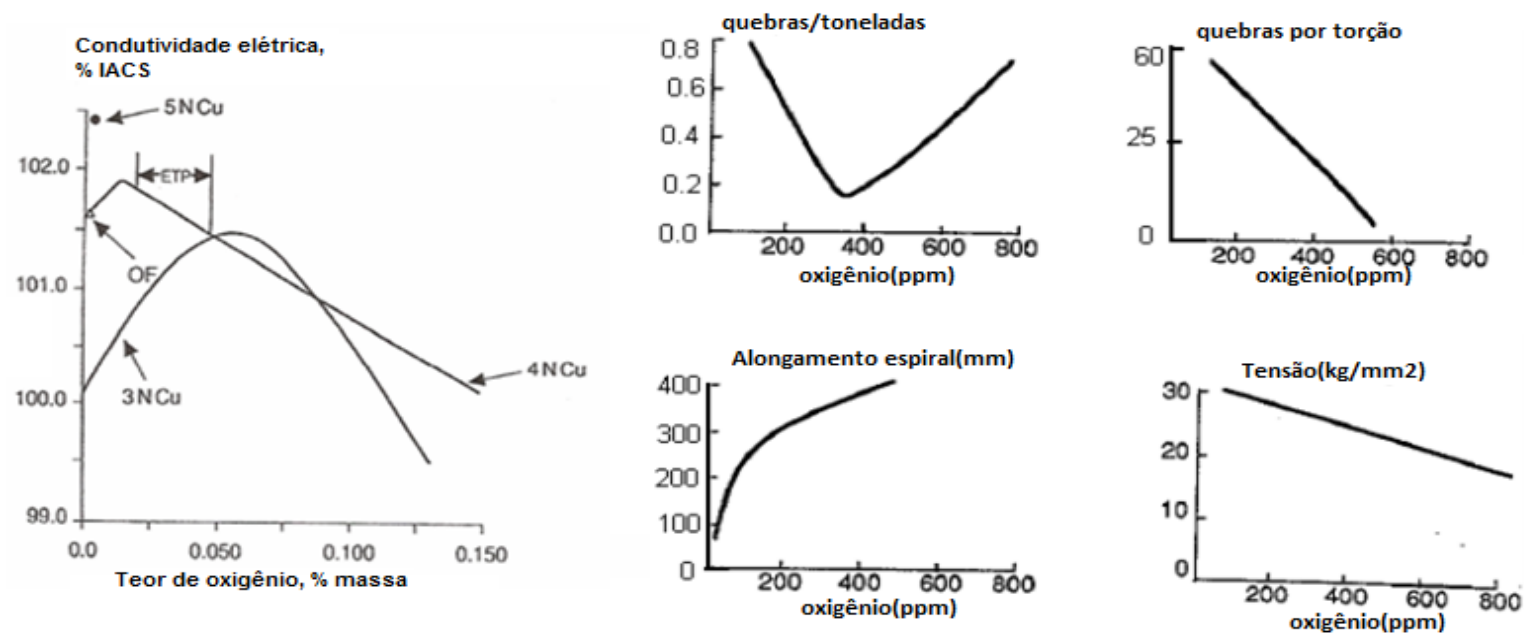

Figura 2. Efeito do teor de oxigênio na condutividade elétrica do vergalhão de cobre recozido. A figura mostra um máximo para 200ppm de oxigênio para o Cu 99,99\% e máximo perto de 500ppm para Cu 99,9\% e influencia do teor de oxigênio sobre outras propriedades mecânicas e físicas do vergalhão de cobre [1]. 
O valor ótimo para condutividade elétrica está próximo a 200ppm, mas teores maiores de oxigênio aumentam o alongamento espiral (S.E.N.), diminui o esforço durante a etapa de trefilação e aumenta a ductilidade. Mas antes de definir o teor ótimo de oxigênio que corresponde a melhores propriedades mecânicas e elétricas é necessário avaliar o teor das impurezas presente no cobre $[1,5]$.

Por exemplo, existe boa correlação encontrada entre alongamento no ensaio chamado ARTest e o teor total de impurezas dividido pelo teor de oxigênio. Este princípio baseia-se na ação de coleta e limpeza que o oxigênio tem sobre as impurezas deletérias na recristalização [3].

Há uma forte correlação entre a influência do teor de oxigênio e a recristalização de cobre. Com o um cálculo estatístico baseado em aproximadamente 500 testes, foi possível observar que: os testes de alongamento espiral (SEN) e o AR-test aumentaram diretamente proporcional ao teor de oxigênio no vergalhão, conforme mostra a Figura 3 [7].

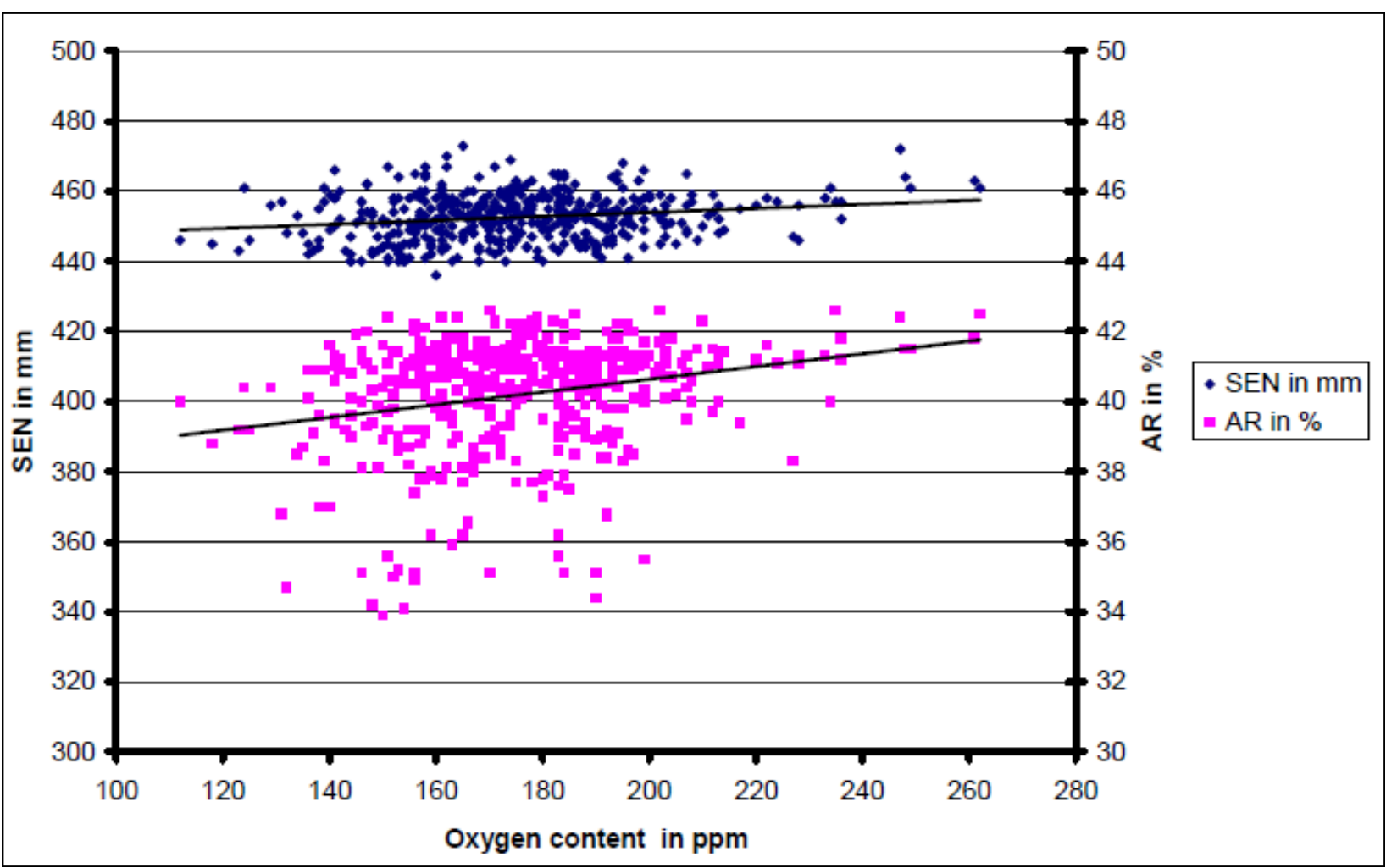

Figura 3. Influência do teor de oxigênio sobre o alongamento espiral (SEN) e o AR-test [7].

Segundo Schmidt o resultado do teste alongamento espiral (SEN) para o vergalhão livre do oxigênio (OFE) é bem inferior ao vergalhão ETP [7]. Comparando o vergalhão de cobre livre de oxigênio (OFHC) com o vergalhão de cobre ETP, o OFHC tem, além de um custo elevado, outra grande desvantagem em relação ao ETP, que é a alta temperatura de recristalização. As impurezas não conseguem precipitar em contornos de grão e permanecem em solução sólida; não há tratamento térmico que resolva isto. Por este motivo, no vergalhão de cobre contendo impurezas, a presença de oxigênio pode ser benéfica para a deformação a frio [3]. 


\section{MATERIAIS E MÉTODOS}

Para verificar os efeitos que o teor de oxigênio pode causar nas propriedades do cobre serão realizados alguns ensaios conforme descrito abaixo.

\subsection{Análises de Oxigênio}

Para análises e emissão do certificado de produtos de cobre é utilizado o método Gasometria por Combustão no aparelho LECO (modelo: RO-416 BR). Sendo que a metodologia utilizada para realizar as análises de medição contínua de oxigênio e através de célula eletroquímica que gera uma milivoltagem dependente da atividade do oxigênio no cobre líquido. O aparelho utilizado é o CELOX (Modelo: Lab E) com o sensor CONCELOX.

Foram utilizados duas amostras de vergalhões com teores de oxigênio diferentes: $O$ vergalhão A com 235ppm e o vergalhão B com 134ppm. O oxigênio foi analisado no laboratório utilizando a metodologia de Gasometria por Combustão no aparelho LECO.

\subsection{ARTest}

O ARTest é ensaio mecânico foi introduzido recentemente para avaliar a qualidade do cobre. Trata-se de um ensaio rápido que, segundo as entidades proponentes, este ensaio é capaz de testar com bastante eficácia a ductilidade em vergalhões de cobre produzidos por laminação a quente. Os vergalhões A e B foram submetidos ao ensaio de ARTest. Os fios trefilados foram ensaiados em tração em uma máquina de ensaios de tração INSTRON (modelo 3367).

\subsection{Análise metalográfica}

Os vergalhões ensaiados foram embutidas para caracterização microestrutural. Foi feito lixamento em lixas até grana 1200, polimento com pasta de diamante 6, 3 e $1 \mu \mathrm{m}$ e polimento final em sílica coloidal. $\mathrm{O}$ ataque metalográfico foi feito em solução de $\mathrm{NH}_{4} \mathrm{OH}+\mathrm{H}_{2} \mathrm{O}_{2}$.

Utilizando um Microscópio Ótico (MO) foi analisada a fração de grãos recristalizados nas amostras submetidas aos tratamentos de recozimento em óleo por 8 minutos.

\subsection{Medias de dureza}

As amostras foram ensaiadas em microdurômetro Vickers ZWICK com carga de $300 \mathrm{~g}$, para determinação das durezas HV 0,3 das amostras.

\section{RESULTADOS E DISCUSSÃO}

\subsection{Medição continua de oxigênio}

Com a medição continua do teor de oxigênio no banho de cobre antes de solidificar o metal foram verificamos diversos ganhos de para o processo menor exposição dos operadores a temperatura para retirar amostras de cobre e menor contato com a palanquilha, redução de análises no laboratório, aumento da eficiência da laminação, reduzir o tempo de lingotamento nas partidas da laminação (Figura 4), reduzir a 
quantidade de bobinas recusadas pelo teor de oxigênio fora da faixa especificada (Figura 5).

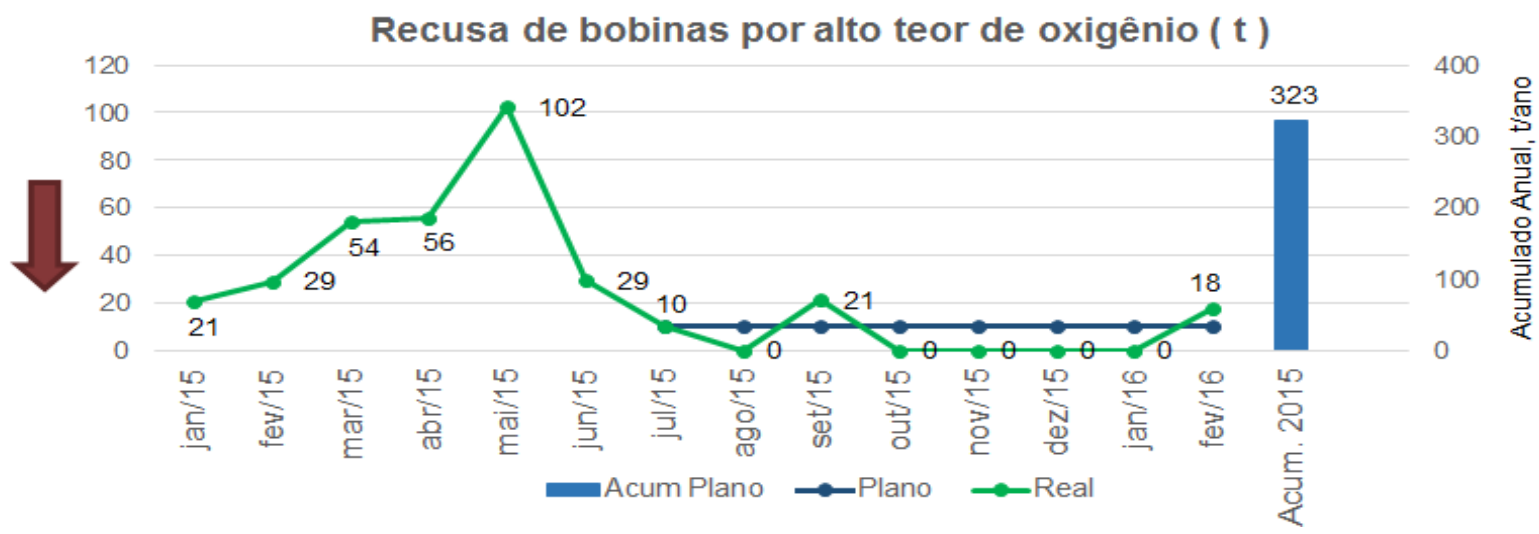

Figura 4. Mostra que após a medição continua de oxigênio, no segundo semestre/2015 com a utilização do sensor obteve-se redução de $90 \%$ na geração de bobinas recusadas em relação ao primeiro semestre

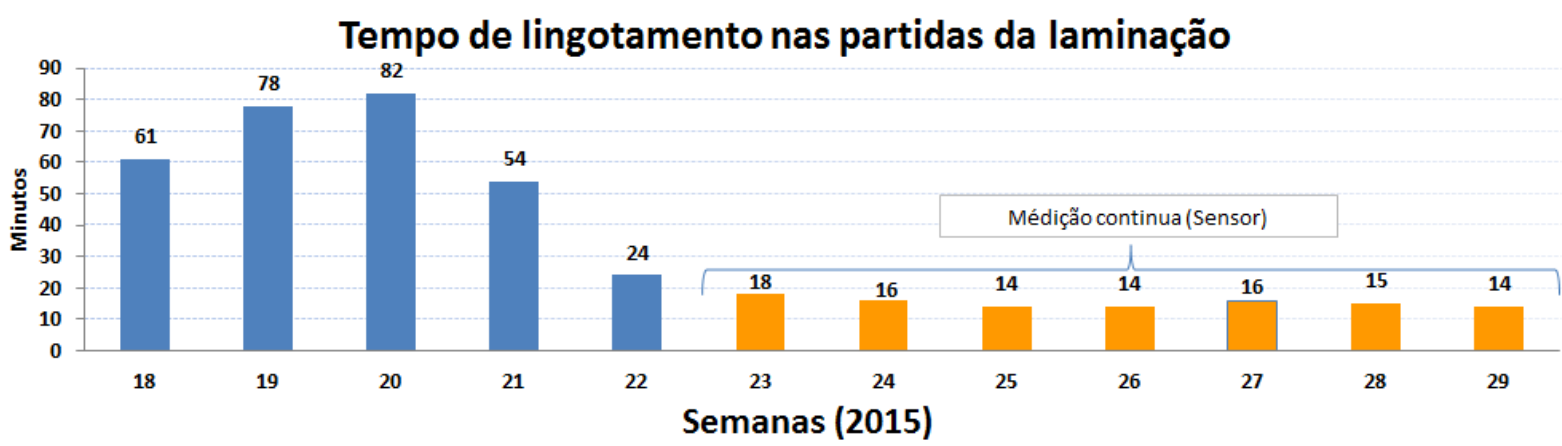

Figura 5. Mostra que após a medição continua de oxigênio, o tempo médio reduziu $75 \%$ para estabilizar o oxigênio.

Além dos ganhos de processo citados acima, a menor variabilidade do teor de oxigênio no vergalhão e o teor de oxigênio adequado ao processo obteve melhores propriedades elétricas e físicas para o produto de cobre.

$O$ vergalhão $B$ apresentou alongamento de $14 \%$ no ensaio de ARTest e o vergalhão A apresentou alongamento de aproximadamente $45 \%$. Sendo que o mínimo necessário para o ensaio de ARTest é que o vergalhão apresente completa recristalização com alongamento superior a 35\%. A diferença observada pode ser previamente justificada pela diferença entre os teores de oxigênio.

\subsection{Análise metalográfica}

$\mathrm{Na}$ análise metalográfica das amostras $\mathrm{A}$ e $\mathrm{B}$ após a trefilação no laboratório, com deformação de diametro de $8 \mathrm{~mm}$ para $6,3 \mathrm{~mm}$ e recozimento a $260^{\circ} \mathrm{C}$ durante 8 minutos, a amostra do vergalhão $A$ apresentou estrutura $100 \%$ recristalizada, enquanto a amostra do vergalhão B não recristalizou 100\%. A figura 6 apresenta a micrografia observada no $\mathrm{MO}$ das amostras de vergahão A e B. 

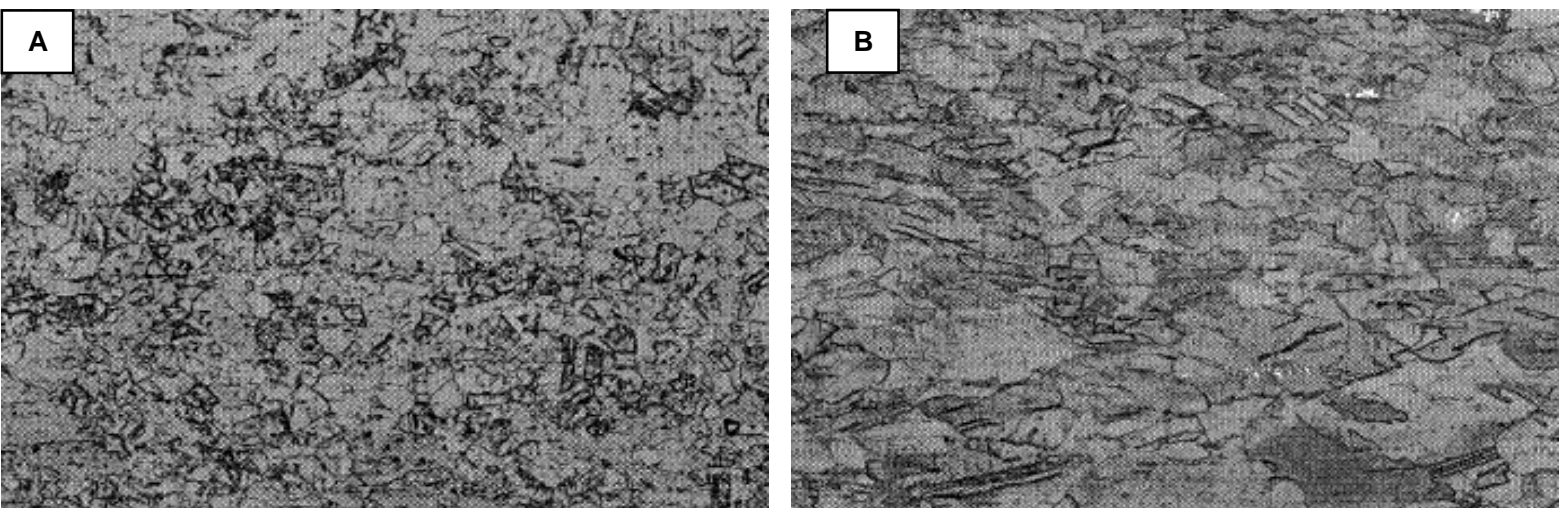

Figura 6. Amostras do vergalhão A e B após trefilação de $8 \mathrm{~mm}$ para 6,3mm e tratamento de recozimento a $260^{\circ} \mathrm{C}$ durante 8 minutos. Ataque: $\mathrm{NH}_{4} \mathrm{OH} / \mathrm{H}_{2} \mathrm{O}_{2}$. Aumento: $200 \mathrm{X}$.

De acordo com a micrografia da Figura 6 é possível observar que a amostra B apresenta grãos alongados na direção de trefilação, indicando que o tempo e temperatura de $260^{\circ} \mathrm{C}$ e 8 minutos não foram suficientes para promover a recristalização total.

\subsection{Medidas de dureza}

Foram feitas medidas de dureza Vickers HV 0,3 das amostras analisadas metalograficamente. Os vergalhões brutos de laminação com $8 \mathrm{~mm}$ de diâmetro foram trefilados em laboratório para diâmetro de $6,3 \mathrm{~mm}$, com $38 \%$ de redução em área, sendo em seguida recozidos em banho de óleo por 8 minutos, em temperaturas entre 240 e $290^{\circ} \mathrm{C}$, no equipamento utilizado no procedimento ARTest. As amostras assim obtidas foram submetidas aos ensaios de dureza Vickers HV 0,3, conforme mostra a figura 7.
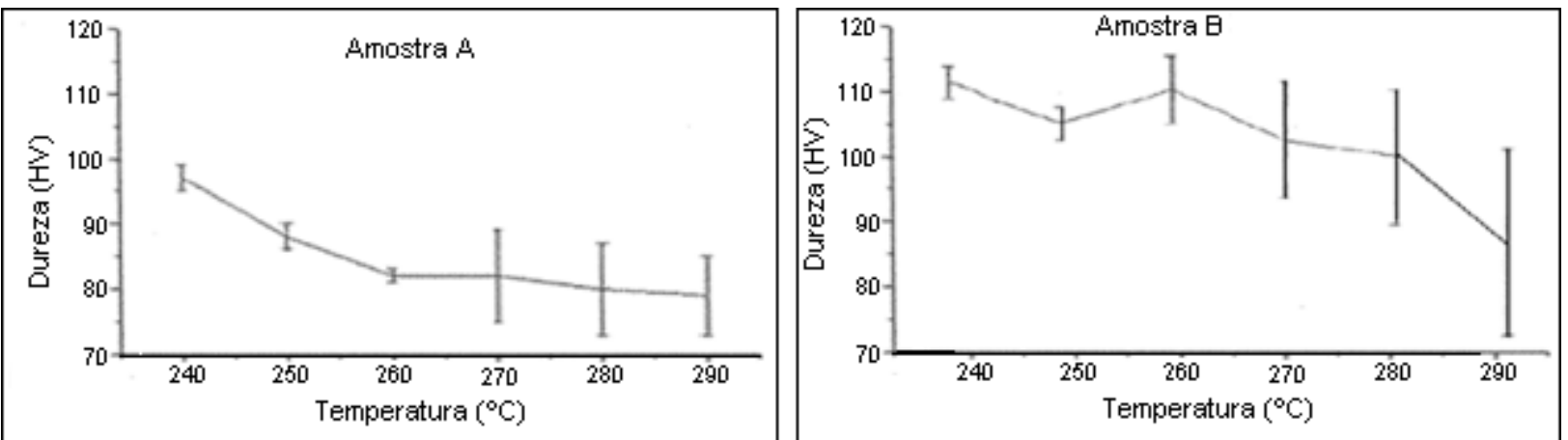

Figura 7. Variação de microdureza Vickers HV 0,3 de amostras A e B em função da temperatura de recristalização para ARTest.

A seguir é feita uma discussão desse resultado à luz de referências existentes a respeito na literatura.

A literatura sobre cobre para condutores enfatiza a importância da ductilidade e condutividade elétrica elevada em relação a um elevado limite de escoamento. Para que possam ser conformados plasticamente sem maiores problemas, esses materiais são normalmente recozidos de forma a sofrer recristalização plena, pois quando o recozimento ocorre em baixas temperaturas, o resultado é a economia de energia e processos melhorados. Portanto, o efeito do baixo teor oxigênio no atraso da cinética da recristalização passa a ser muito importante. 
As principais conclusões de Pops encontram-se resumidas em um trabalho recente em que afirma que teores muito baixos de oxigênio não são utilizados, pois favorecem a formação de trincas a quente e aumento da temperatura de recristalização ou do tempo necessário para recristalização completa. Por outro lado, teores muito elevados reduzem a condutividade e a conformabilidade a frio; por este motivo Pops recomenda valores na faixa de 175 a 400 ppm de oxigênio e sugere um teor ótimo próximo de 250 ppm [1, 4].

Smets, afirma ser voz corrente entre os produtores que cobre contendo inclusões, seja ela de óxidos ou de compostos metálicos, tem menor ductilidade que o cobre livre de oxigênio (oxigen-free, OF) tem maior ductilidade. No entanto, o OF tem além de um custo elevado, outra grande desvantagem em relação ao ETP, que é a alta temperatura de recristalização. As impurezas não conseguem precipitar em contornos de grão e permanecem em solução sólida; não há tratamento térmico que resolva isto. Por este motivo, em cobre contendo impurezas a presença de oxigênio pode ser benéfica para a deformação a frio [3].

De acordo com esses autores, o efeito do oxigênio é uma função complexa do nível de pureza do cobre e é significativo em cobres com teores de impurezas mais elevados. Embora o assunto seja complexo, a literatura indica sinergismo entre impurezas no aumento da temperatura de recristalização e queda de ductilidade em testes de alongamento. $E$ um efeito benéfico do oxigênio, desde que em teores não muito elevados (> 450 ppm).

Quando o recozimento ocorre em baixas temperaturas, o resultado é a economia de energia e processos melhorados. Estes benefícios são compensados por um aumento ligeiramente concomitante de resistência à tração que é atribuído à presença de óxidos de cobre dispersos. As partículas de óxido não só aumenta à resistência a tração com o aumento do teor de oxigênio, mas elas também têm um efeito estabilizador sobre o tamanho de grão final, que pode ser benéfico. Os efeitos comportamentais do teor de oxigênio no recozimento e na resistência dos fios totalmente recozidos são mostrados esquematicamente na Figura 8, e indicam duas tendências opostas. Do mesmo modo que o teor elevado do oxigênio pode prejudicar a ductilidade, baixo teor de oxigênio dificulta o recozimento [4].

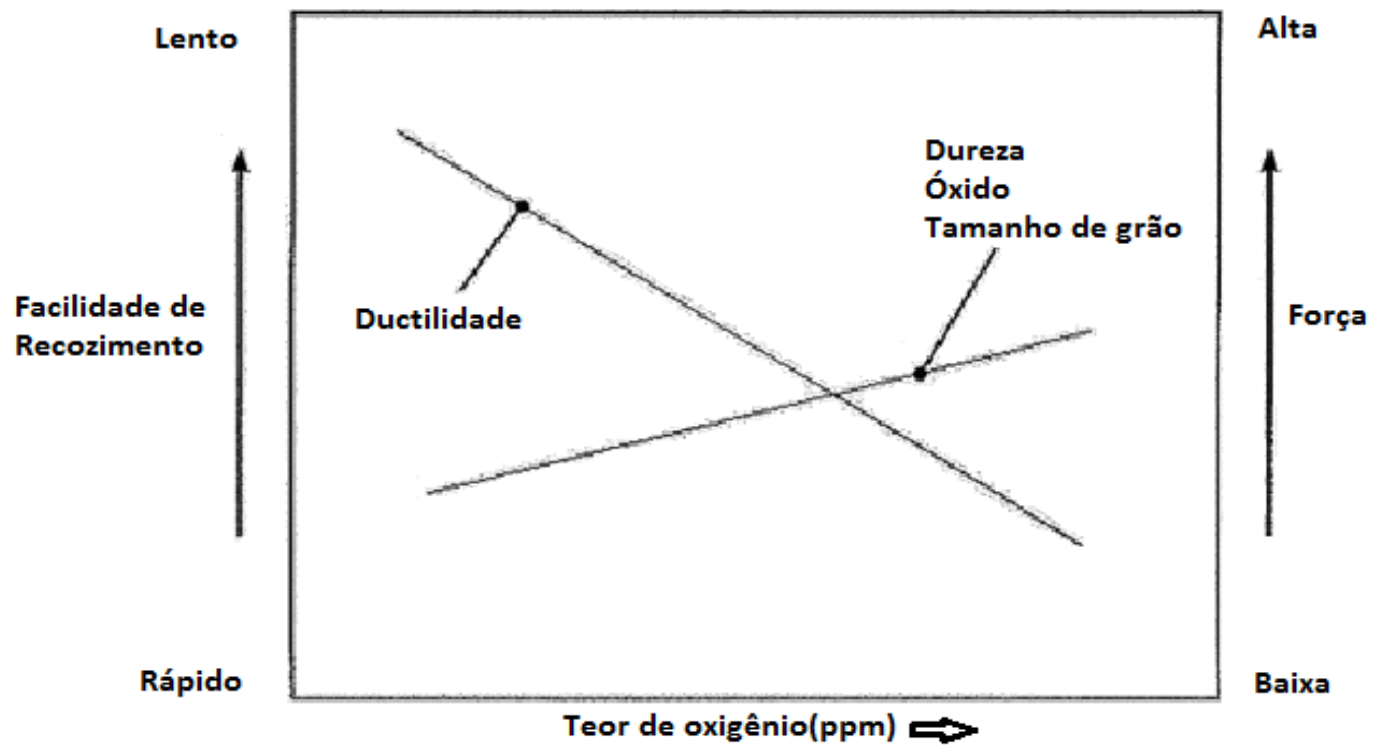

Figura 8. Representação esquemática mostrando os efeitos do teor de oxigênio sobre o recozimento e o endurecimento do vergalhão [4]. 
Portanto, o controle sobre o teor de oxigênio, dissolvido no cobre líquido, é muito importante para garantia da qualidade do vergalhão. O cobre com alto teor de oxigênio (entre 350 e 600ppm) tende a abaixar a condutividade e tornar o vergalhão, ou fio de cobre, quebradiço. Por outro lado, o baixo teor de oxigênio no vergalhão de cobre pode prejudicar a condutividade elétrica e a recristalização. Logo, durante a produção do vergalhão o objetivo é minimizar as variações bruscas do teor de oxigênio, para garantir a qualidade do produto e, conseqüentemente, melhorar a conformação mecânica do vergalhão.

\section{CONCLUSÃO}

- Os ganhos obtidos ao realizar a medição continua do teor de oxigênio no banho líquido foram:

- No segundo semestre de 2015 a geração de bobinas recusadas por alto teor de oxigênio foi $90 \%$ menor que no primeiro semestre.

- Reduzido o tempo de lingotamento nas partidas para próximo á 20 minutos. Apesar de ter outras variáveis que impactam nesse resultado.

- Houve redução na exposição ao calor para retirada de amostras na calha II e na amarração de palanquilhas.

- Menor variabilidade do teor de oxigênio no vergalhão produzido e valores entre 200 e 250ppm, proporcionando melhores propriedades elétricas e físicas para os produtos de cobre.

- Ao trefilar o vergalhão com teores de oxigênio adequados haverá economia de energia durante o processo de recozimento, redução das quebras e maior condutividade elétrica do fio de cobre produzido.

\section{REFERÊNCIAS}

1 Pops H. Non Ferrous Wire Handbook. Principles and Practice. 1995; 3: 7-21; 143-154.

2 ASTM B 49 - 98. Normas Técnicas. Other Requerements. 2014; 1 - 3.

3 Smets J, Mortier R. The Influence of Oxygen During Hot Rolling and Drawing of Continuous Cast Rod. Wire Assoc. International. 1983; 53: 14-18; 266-281

4 Pops, H. Influence of oxygen in copper. Tech News Magazine. 2010; 5: 230-232.

5 Feyaerts K, Huybrechts P; Schamp J; Van Humbeeck J; Verlinden B. The effects of impurities on the recrystallization behvior of tough-pitch hot rolled copper rod. WIRE JOURNAL INTERNATIONAL. 1996. 5: 68 - 76.

$6 \quad$ Jakani S. Effet des impuretés sur les mécanismes de recristallisation du cuivre tréfilé. UNIVERSITE PARIS SUD - ORSAY U.F.R. Scientifique d'Orsay (tese). 2004.

7 Schimdt J; Jacobsen J. Recrystallization of copper wire rod. 2007. 1:203 - 211. 